LII.

Aus dem Thierphysiologischen Institut der Berliner landwirtschaft1. Hochschule.

\title{
Ein neuer Apparat zur Bestimmung des Sauerstoffgehaltes und der Kohlenoxydcapacität des Blutes.
}

\author{
Von \\ Dr. Johann Pleseh (Budapest). \\ (Mit 2 Abbildungen im 'T'ext.)
}

Müssen wir auch die Pumpen-Blutgasanalyse als die exacteste anschen, so wurde sie doch wegen der schweren und umständlichen Methodik und wegen der erforderlichen theueren Einrichtungen, nur von verhältnissmässig wenig Forschern cullivirt.

Diesen Umständen ist es zuzuschreiben, dass die physiologisehen wie die pathologischen Fragen, die mit den Blutgasen in Zusammenhang. stehen, nur sehr wenig aufgearbeitet sind und noch einer Lösung harren.

Es hat somit jedes Verfahren, welches die Blutgasanalyse ohne Pumpen ermöglicht, ein gewisser Interesse zu beanspruchen. Ich gebe in dieser Abhandlung ein Verfahren an, mit welehem wir nicht nur den Sauerstoffgehalt, sondern auch die Kohlenoxydcapacität, Kohlensäurcgehalt und eventuell die Gasspannung des Blutes auf einfache Weise und in relativ kurzer Zeit und mit ausreicheuder Genauigkeit bestimmen können.

\section{Beschreibung des Apparates ${ }^{1}$ ).}

Der Apparat, den ich bei meinem Verfahren gebrauche, besteht aus zwei Haupttheilen, und zwar aus dem Gasanalysen- und aus dem Absorptionstheil. Im Gasanalysentheil haben die allgemein gebrauchten Kalilauge- und Pyrogallatpipetten Anwendung gefunden und zwar in der von Haldane empfohlenen Anordnung. Natürlich musste auch dieser Theil dem Absorptionstheil und den Versuchen entsprechend geändert werden.

Die Gasmessröhre Il (Fig. 1) dient zur Aufnahme von Gasen. Er kann oben mit einem T-Hahn entweder verschlossen oder mit dem Blutrecipienten I oder mit den Pipetten VI und IV communiciren. Die

1) Der Apparat wird in der Glastechnischen Werkstätte von Bleckmann und Burger, Berlin, Auguststr. 3 verfertigt. 
Hessröhre ist so calibrirt, dass der obere Theil $30 \mathrm{cem}$ Inhalt hat und der ausgezogene Theil $5 \mathrm{ccm}$. Der $5 \mathrm{ccm}$ fassende Theil ist auf $0,02 \mathrm{ccm}$ eingetheilt und ermöglicht noch eine ziemlich genaue Schätzung in der dritten Decimale. Dic Messröhre communicirt mit dem Quecksilberbehälter 2, mit dessen Hülfe in der Vessröhre Gas eingesaugt oder hinausgetrieben werden kann. Hahn $\mathrm{C}$ hat ebenfalls eine 'T-Bohrung und kann die Pipette IV mit der Messröhre oder mit der Pipette VI verbinden.

Pipette IV ist mit zahlreichen dünnwandigen Glasröhrchen gefüllt und trägt jm capillaren oberen Theil eine Marke. Am unteren Ende ist sic communicirend mit dem Behälter 4 und der Capillare V verbunden. Die Capillare trägt in derselben Höhe wie IV eine Marke und ist durch cinen T-Hahn mit der Gasbürette III verbunden. - Der Hahn d stellt eine Verbindung her zwischen III und V und zwischen III und Aussenluft und $V$ und Aussenluft.

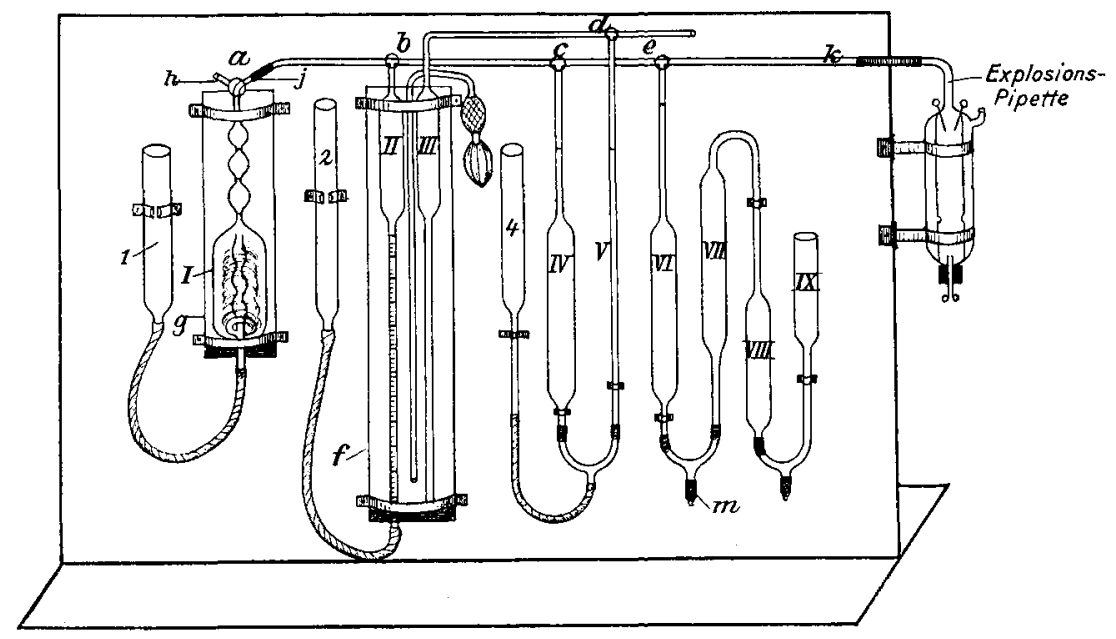

Fig. 1.

III ist am unteren Ende cingeschmolzen und hat ebenfalls 35 ecm Inhalt wie die Messröhre II.

Pipette VI trägt am oberen Ende nahe an der Capillarenmündung eine Marke und ist ebenfalls mit dünnwandigen Glasröhren grefüllt. Durch den 'T-Hahn o kınn dic Pipette verschlossen oder mit IV verbunden werden, oder es kann mit Hülfe des Hahnes der Weg nach der Explosionsprpette hergestellt werden. Die Pipette VI communicirt mit VII, VIII und IX.

Die Röhren II und IIJ sind in einem mit Wasser gefüllten Cylinder untergebracht, welcher von unten mit einem Gummistopfen gedichtet ist. Der Inhalt des Wassermantels wird mit Hülfe eines Doppelgebläses gleichmässig durchgemischt.

T hat : an oberen Ende den Dreiweghahn a, wodurch es mil den Capillaren $\mathrm{j}$ und $\mathrm{h}$ in Verbindung zu bringen ist. 
Die drei Kugeln der Recipienten I gehen durch Capillaren in einander über und sind durch Marken ahgegrenzt. Die Kugeln sind inclusive der Hahnbohrung calibrirt und jede Kugel fasst zwischen 2 Marken ca. $2 \mathrm{ecm}$.

Unter den Kugeln erweitert sich der Recipient in ein cylinderförmiges Gefäss, in welchem zur Vergrösserung der Oberfläche eine Glasröhrenspirale und mehrere Kugeln eingeschmolzen sind; Glasröhren sind hier darum nicht anwendbar, weil sie durch das Quecksilber gehoben und an die Wand des Cylinders gepresst werden, wodurch Iuftblasen zurückgehalten werden. Der Recipient ist mit dem Quecksilberbehälter 1 verbunden.

Der Apparat kann auf versehiedene Weise gebraucht werden und ist durch geringe Aenderungen für die meisten Gasanalysen ausreichend.

\section{Gebrauch des Apparates.}

Bei Luft- oder Gasgemischanalysen wird die Messröhre II durch eine durchwegs getheilte cylindrische Röhre ersetzt, sowie die Röhre III, die den gleichen Inhalt haben muss wie II.

Das Verfahren mit diesem Apparat ist bei einer Gasanalyse folgendes:

Pipette IV und Capillare $V$ wird von 4 aus mit 20 proc. Kalilauge gefüllt, " und zwar werden die Hähne a, b und c dabei so gestellt, dass die Pipette bei $h$ und die Capillare $V$ bei $d$ nach aussen offen steht.

Ebenso wird durch einen Sehlauch, der bei $m$ angebracht wird, die Pipette VI und der Behälter VII mit alkalischem Pyrogallai gefüllt. Gegen die Aussenluft wird das Pyrogallat von den mit concentrirter Kalilauge gefüllten Behältern VIII und IX geschützt. Die Behälter VIII und IX müssen vor dem Einfüllen des Pyrogallats in die Pipette gefüllt werden. Der Hahn e wird so gestellt, dass die Pipette VI nach aussen communicirt.

Durch den Schlauch bei $m$ wird mit Hülfe eines Trichters das Pyrogallat eingefüllt.

Das Eudiometer II wird von 2 ans mit Quecksilber gefüllt.

Um mit der Wasserdampfspannung nicht rechnen zu müssen, bringen wir einen kleinen Tropfen schwach angesäuertes Wasser in die Messröhre.

Um den Apparat für eine Analyse gebrauchsfertig zu machen, sind folgende Dinge zu beachten. Die T-Hähne b, e und e werden so gestellt, dass II mit VI verbunden wird. Durch Senken des Quecksilberbehälters 2 wird das Pyrogallat bis zur Marke hinaufgesaugt und jetzt die Pipette durch entsprechende Stellung von e versperrt.

Bei der Einstellung der Kalilauge auf die Marke wird II mit IV verbunden und ebenfalls von 2 aus bis zur Marke aufgesaugt. Ist dies geschehen, so wird Hahn b gegen a gedreht und der Stickstoff aus dem Eudiometer herausgetrieben. Jetzt wird das capillare Ende h mit dem Gasometer verbunden und durch Senken von 2 das zu untersuchende Gas in II eingesaugt. 
Lm die Druck- und Temperatursehwankungen nicht berücksichtigen zu müssen, dient der angebrachte und gleich zu beschreibende, von Haldane angegebene Thermobarometer.

Wird der T-Hahn d so gestellt, dass III und $V$ mit der Aussenluft communiciren kann, so wird die Kalilauge in der Capillare V durch Heben und Senken von 4 in derselben Höhe wie in IV eingestellt werden können. Verbinden wir durch entsprechende Hahnstellung von $c$ und $b$ der Messröhre II und die KOH-Pipette IV, so wird, wenn das Gas in II unter atmosphärischem Druck steht, das Niveau der Kalilauge in 4, IV und $\mathrm{V}$ in gleicher Höhe stehen, da in allen drei Gefässen ebenfalls atmosphärischer Druck herrseht. Ebenso wird auch im Gefäss III atmosphärischer Druck sein. Drehen wir jetzt den Hahn d derart, dass bei Abschluss von der Aussenluft III und IV communicirt, so ist die Luft bei atmosphärischem Druck und bei der Temperatur im Wassermantel f eingespert. Unter denselben Bedingungen steht das Gas in die Messröhre II. Das Princip des Haldane'schen Thermobarometers besteht darin, dass das Volum des Gases im Thermobarometerrohr durch cine Druckvariation, welche mit Hülfe von Rohr 4 ausgeübt wird, constant erhalten wird. Sobald wir dann durch Verschieben des Niveaurohrs 2 den Stand der $\mathrm{KOH}$ in IV auf den ursprünglichen Stand gebracht haben, herrseht in II derselbe Druck, den wir eben in III behufs Einstellung auf das ursprüngliche Volumen erzeugt haben.

lst nun das Eudiometer mit dem zu untersuchenden Gas gefüllt, so wird das Gasvolumen bei der Einstellung auf den Marken in der Messröhre abgelesen.

Zur Bestimmung der Kohlensäuremenge wird das Gas in die Kalilaugepipette IV getrieben. Tach mehrmaligem Zurücksaugen und Hinübortreiben ist in ca. 2 Minuten sämmtliche Kohlensäure absorbirt. Es wird jetzt das Gasvolumen festgestellt, indem wir dic Kalilauge in der Pipette IV bis ca. in die Höhe der Marke hinaufsaugen, den Wassermantel gründlich mischen, durch Höhen-Verschiebung von 4, in der Capillare V die Lauge auf die Marke einstellen, und endlich präcise mittelst Heben oder Senken von 2, auch in IV die Lauge auf die Marke einstellen.

Bei jeder Volumablesung ist diese Folge zu beachten.

Nach der Kohlensäureablesung wird das Gas in die Pyrogalluspipettc getrieben und hier von Sauerstoff befruit; dabei werden dic Hähne so gestellt, dass II und VI mit einander communiciren und der kurze Schenkel der 'T-Bohrung von e nach oben steht, wodurch bei Abschluss von IV der Capillarenweg frei wird.

Das nach der weiter unten angegebenen Art hergestellte alkalische Pyrogallat absorbirt bei der grossen Oberfläche, welche durch die in der Pipette befindlichen Glasröhren gegeben ist, binnen 5-6 Minuten sämmtlichen Sauerstoff. Wir erkennen die Beendigung der Absorption daran, dass das Pyrogallat, welches bei Anwesenheit von Sauerstoff in dicker brauner Schicht an der Wand der Pipette langsam herunterfliesst, sobald die Absorption vollendet ist, rasch, ohne an der Wand kleben zu bleiben, zurückfliesst. Dic Pipette ist dann durchsichtig und nur ein wenig 
Ein neuer Ipparat zur Bestimmung des Sauerstolfgehaltes etc.

grünlich colorirt. Ist sämmtlicher Sanerstoff absorbirt, so wird das Pyrogallat bis zur Marke hinaufgesaugt und durch eino 1/8-Drebung des Hahnes e die Pipette VI verschlossen. Das nach der Sauerstoffabsorption zurückgebliebene Gasvolumen wird auf die oben beschriebene Art eingestellt und abgelesen.

Bei Luftanalysen giebt der Rest den Stickstoff. Man thut gut, vor jeder Analyse durch Absorplion der Kohlensäure und des Sauerstoffs die todten Rüume des Apparates vorerst auf die beschriebene Wrise mit Stickstoff zu fïllen.

Für Luft- und Respirationsgasanalyse würde die Bestimmung des Sauerstoffs, der Kohlensüure und des Stickstoffs genügen.

Zur Bestimmung des Kohlenoxyds kann die weiter unten für Sauerstoffcapacität-Bestimmung des Blutes beschricbene Methode angewendet werden. Abrr es ist mit dem Apparate auch möglich, das (0) durch Verpuffung zu bestimmen.

Dazu dient die Explosionspipette von $/ / \mathrm{unt}^{1}{ }^{1}$ (Fig. 1), die am Apparat so angebracht werden kann, dass sie linter die Wand des Apparates zu klappen ist, damit durch Explosion der Pipette bei event. zu starker Verpuffung nicht der ganze Apparat leide. Es ist dies nur eine Vorsichtsmaassregel, die bisher noch durch keinen Unfall begründet ist.

Handhabung des Apparates bei Blutgasanalyse.

Um mit dem Apparate Blutgasanalysen ansiellen zu können, gestaltet sich das analytische Verfahren folgendermaassen:

Von h aus wird die Messröhre mit reinem Kohlenoxyd gefüllt. Das Kohlenoxyd ist am zweckmässigsten aus Oxalsäure und Schwefelsüur. herzustellen. Bei gelindem Erwärmen entsteht aus

$$
\mathrm{CO}_{2} \mathrm{H}, \mathrm{CO}_{2} \mathrm{H}=\mathrm{CO}_{2}+\mathrm{CO}+\mathrm{H}_{2} \mathrm{O},
$$

wir müssen somit, um die Kohlensäure zu absorbiren, das Gas durch einen Natronkalkthurm leiten. Damit wir das Gas stets vorräthig haben, kann es in einem Gasometer aufgefangen werden, aus welchem wir dann den Apparat füllen können.

Es ist gut, wenn wir vor dem Versuch das Gas in die Lauge und in das Pyrogallat treiben, um es von event. Sauerstoff oder Kohlensäure zu befreicn.

Der Apparat wird dann eingestellt und das CO-Volumen abgelesen. Jetzt wird der Dreiweg-Hahn a (Fig. 1) so gestellt, dass eine Verbindung zwischen I und zwischen der Capillare $h$ geschaffen wird.

Von Quecksilberbehälter 1 aus wird der Recipient und die Capillare h mit Queeksilber gefüllt. Es ist wichtig, dabei darauf zu achten, dasss weder an den Wandungen noch in den eingeschmolzenen Spiralen und Kugeln Luftblasen kloben bleiben. Bei roinem und trockenem Gefäss und bei langsamen Heben des Füllgefässes ist die Gefahr nicht gross. Doch thut man gut, nachdem der Recipient vollkomm'n mit Qu'cksilber

1) Beschrieben von Preti, Zeitschr. f. Biochemie. 
gefüllt ist, den Hahn a abzusperren und dann den Quecksilberbehälter tief zu senken. Durch d'n im Innern d's Gefässes entstehenden starken negativen Druck werden die Luftblasen frei, sammeln sich im oberen Theil des Gefässes und können dann hinausgetrieben werden.

Um in den Recipienten Blut saugen zu können, ist es zwerkmässig, mit einer Gummiverbindung an $h$ eine Capillare anzubringen. Diese Capillare tauchen wir in ein mit Blut gefülltes Gefäss und saugen daraus durch vorsichtiges Senken von 1 je nach der Menge des vorhandenen
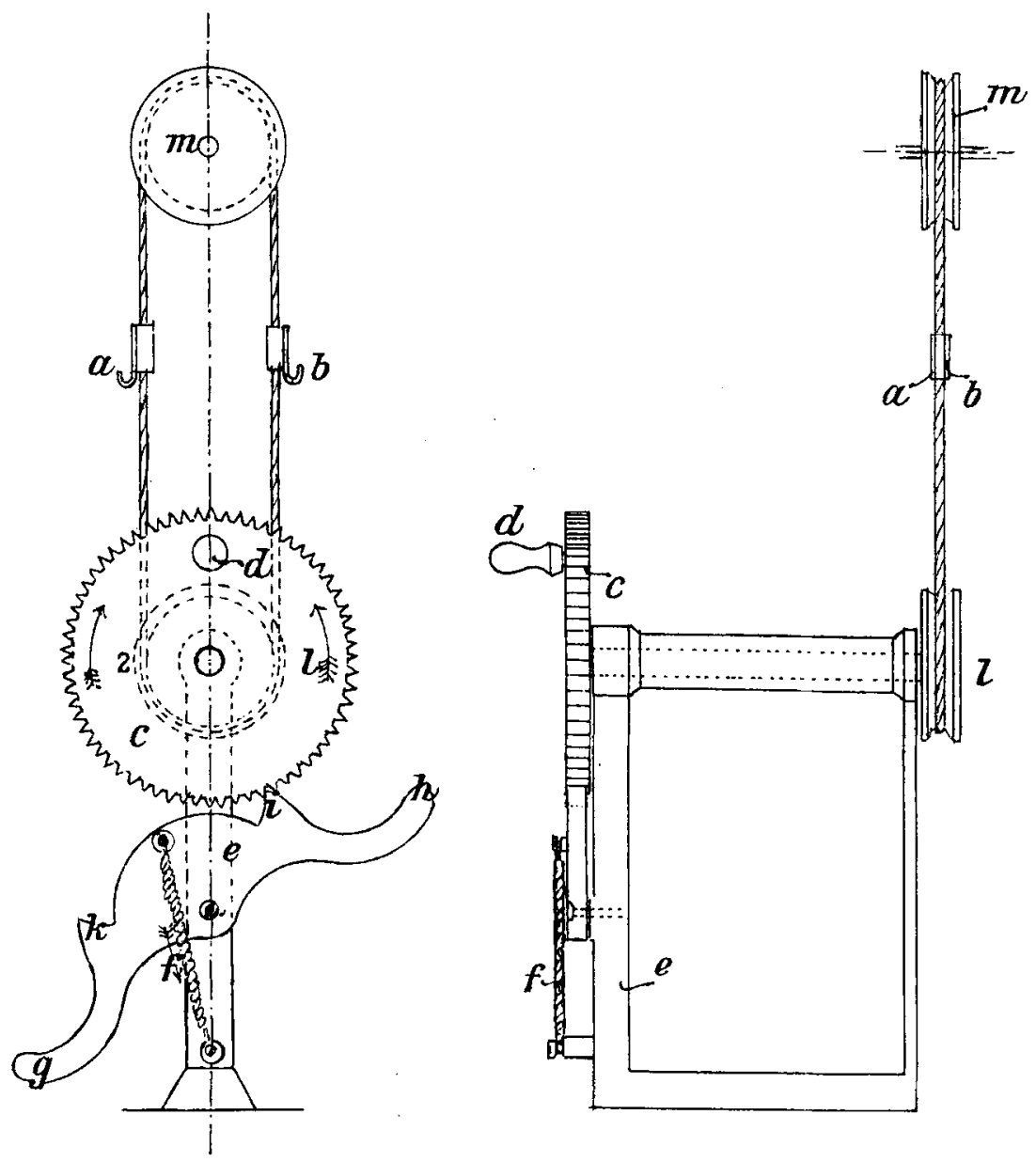

Fig. 2.

Blutes eine, zwei oder alle drei Kugeln des Recipienten bis zur Marke voll. Jetzt drehen wir den Dreiweghahn a gegen das Eudiometer, den Hahn b gegen I und treiben vorsichtig, damit kein Schaum entsteht, CO zum Blut herüber. Sunken wir dabei 1, ohne 2 zu heben, so wird das Gas unter negativem Druek soin, oder heben wir 2, ohne 1 zu senken, so ist das CO unter positivem Druck. Um die Einstellung bri der $\Lambda$ blesung des Gasvolumens sicherer zu gestalten, habe ich als einen Ergäuzungstheil bei dem $\Lambda$ pparate oinen Schnurlauf angewendet (Fig. 2). 
Eine in sich geschlossen" Schnur ist iber rin in $1 \mathrm{~m}$ Höhe befestigtes, mit einer tiofen Rille vorsehenes und um seine Axe frei drehbares Rad m gezogen. Dir Sohnur läuft unten rbonfalls in der Rill. cines Rades 1, welches mittelst eines Hebels d gedreht werden kann. In der Axe dieses Rades ist auch rin Zahnrad o angebracht, welches wir in zwei Richtungen trehen und arretiren können, je nachdem der linke (k) oder der rechte (1) Zahn eines durch die Stahlfedir I' bequem verstellbaren Hebels e eingestellt wird. Die angespanntr Schnur läuft somit circulär. Es ist klar, dass zwei in dor Ruhestollung gegen einander stehende Punkte der Schnur bri dem Drohen sich in rntgegengesetzter Richtung bewegen werdin, und der eine davon ebenso viel steigt, wie der andere sinkl. Wrnn wir somit in einer gewissen Höhe zwei Haken a nnd b an die Schnur inbringen, wolchen wir die Quecksilberbehälter 1 tinel 2 anbaingen, so wird in den communicirenden Gefässen I und II befindliches Gas mnter cinem Drwek stehen, welcher bei der compensirenden Brwegung des ein'n bä̈lters nach unten, des anderen nach oben unveründert bleiben muss, wonn die Gefässe gleich gross sind. Durch diese Vorrichtung ist daher nicht nur die Sicherheit beim Arbeiten erroicht, sondern dic Möglichkeit gegeben, die Sättigung des Blutes mit Kohlenoxyd bri jedem beliebigen Druek vornchmen zu können. Mit dieser Vorrichtung ist anch die Einstellung bei der Ablesung des Gasvolumens auf das Genauleste auszuführen, indem der Radius der Räder ziemlich klein gewählt ist.

Die Sättigung wird um so schneller vor sich gehen, je grössere Oberfläche des Blutes mit dem $\mathrm{CO}$ in Berührung kommt. Beim Schüttelı entstehen Blasen, deren capillare Wände das CO aufnehmen und das CO und $\mathrm{O}_{2}$ abgeben. Die Blasenentstehung muss aber bei diesem Apparat vermieden worden, da sonst eine Abmessung des Gases nicht gut möglich ist. Es ist darum nöthig, durch wiederholtes Heben und Senken der Quecksilbergefässe das Blut zu vermengen, damit immer eine ander Schicht mit dem Kohlenoxyd in Berührung kommt. Die Sättigung des Blutes geschieht, indem das $\mathrm{CO}$ in I getrieben wird, wodurch das Blut in den unteren Theil des Gefässes verdrängt wird. Das Blut versehmiert sich an der inneren Wand der Kugeln, der Spirale und des Gefässes. Um die Sättigung bei beliebiger Temperatur vornehmen zu können, ist I von einem Wassermantel umgebon. Für die bequemste Art, den Wassermantel $g$ auf einer beliebigen Temperatur constant zu erhalten, empfehle ich die Erwärmung durch elektrisehen Strom. Ich gebrauthte dazu eine 10 Kerzen starke Glühlampe von Kerzenform, die an der Fassung mit Guttapercha isolirt war. In den Leitungsdraht schaltete ich einen Schieberrheostat und steckte dann die. Lampe in den Wassermantel. Durch die Verschiebung des Rheostates konnte ich jede beliebige Temperatur bis $42^{\circ}$ constant erhalten. Der Wassermantel ist gross genug, um noch cin Thermometer und eine Mischröhre fassen zu können. Im Laufe der Mischung von Blut und Gas wird nicht nur Kohlenoxyd vom Blute absorbirt und Sauerstoff frei werden. Ausserdem wird wegen der Spannungsdifferenz das Blut virl von seiner Kohlensäure und dem physikaliseh absorbirton Stickstoff verlieren. Es wird somit das Gasgenuisch 
nacb cinig+r Zeit Kohlenoxyd, Sanerstoff, Kohlensäure und Stickstoff enthalten.

Nach längerem Mischen bringen wir dieses Gasgemisch in das Eudiometer zurück, wobei darauf geachtet werden muss, dass auf der Oberfläche des Blutes keine Schaumblasen sich befinden. Etwaiger Schaum ist durch schwache Bewegung des Blutes im obersten capillaren Theil des Blutes ohne besondere Mühe fortzubekommen.

Es muss das Blut so eingestellt werden, dass es die Hahnbohrung des Dreiweghahnes füllt.

Das zurückgezogene Gas wird, nachdem sich die Temperatur ausgeglichen hat, auf das Thermobarometer eingestellt, das Volumen abgelesen und notirt. Dann wirl die Kohlensältre und der Sauerstoff durch A.bsorption bestimmt.

Die Sättigung wiederholen wir so oft, bis keine Absorption von $\mathrm{CO}$ resp. keine $\Lambda$ bgabe von $\mathrm{CO}_{2}$ und $\mathrm{O}_{2}$ mehr erfolgt. d. J. bis das Gasvolumen keine Aenderung mehr zeigt.

\section{Berechnung der Resultate:}

Die Thermobarometer-Einrichtung ermöglicht die procentische Zusammensetzung von Gasgemischen ohne Weiteres zu berechnen.

Bei den Blutgasanalysen müssen wir aber die gefundenen Werthe in absoluten Zahlen angeben. Um das ausführen zu können, sind folgende Punkte zu beachten.

Das CO-Volumen wird bei Atmosphärendruck abgelesen, den wir notiren. Ebenso muss an dem im Wassermantel steckenden Thermometcr dic Temperatur abgelesen werden. Aus dem Volumendruck und Temperatur können wir die Reduction des Gases auf $760 \mathrm{~mm}$ Druck, $0^{0}$ und Trockenheit berechnen. Jedes im Laufe des Versuches mit Hülfc des Thermobarometers abgelesene Gasvolum kann durch einfache Proportion auf $0^{\circ}, 760 \mathrm{~mm}$ und Trockenheit reducirt werden. Wollen wir dic Sauerstoffcapacität des Blutes berechnen, so ist die Temperatur, bei welcher das Blut mit Luft oder Sauerstoff geschüttelt wurde, zu notiren, da die Sauerstoffaufnahmefähigkeit sowie die physikalische Absorption von der Temperatur des Blutes abhängig ist.

Zur Bestimmung der absoluten CO-Capacität des Blutes muss die Temperatur, bei welcher das Blut vor Eitufullung in den Apparat mit Luft gesättigt war, sowie dicjenige, bei wolcher die Behandlung mit CO vorgenommen wurde, bekannt sein, lerner der Druck. Es ist dies darum nöthig, weil wir im Restgas ausser dem Kohlenoxyd noch diejenige Menge ron Stickstoff haben, die im Blute physikalisch absorbirt vorhanden war.

Bei der Berechnung des sich dem CO beimengenden $\mathrm{N}$ nehmen wir an, dass das Blut 92 pCt. derjenigen Stickstoffmenge absorbirt enthält, welche Wasser bei gleicher Temperatur und gleichem Druck aufnehmen würde.

\section{Kritik der Methodik.}

Es fragt sich, ob wir verlüssliche Resultate bezüglich der vier in Erage kommenden Gase bei diesem Verfahren zu erwarten haben. Be- 
züglich des Sauerstoffs, Kohlenoxyds und Stickstoffs kann ich dies ohne Weiteres bejahen, wogegen ich mich bexüglich der Kohlensäure reservirter verhalten möchte.

Wir wissen seit den grundlegenden Untersuchungen ron Hüfner, Bohr und Haldane, dass das Hämoglobin circa $134 \mathrm{mal}$ grössere Affinität zum Kohlenoxyd hat, als zum Sauerstoff ${ }^{1}$ ). Dic Sättigungsdauer mit Co würde sich somit in der capillaren Sclicht fast momentan vollziehen. Die Sältigungsdauer hängt somit von der durch die eingegeschmolzene Spirale und Kugeln bewirkten Vergrösscrung der Oberfläche ab. Bei dem Rewegen des Blates in dem Gefässe verschmiert sich stets eine andere Portion in capillarer Schicht an die Wand des Gefässes. Aus der Spannungsdifferenz erklärt sich auch das quantitative Freiwerden des Stickstoffs.

Es ist eine alte Erfahrung, dass die Kohlensäure das Blut am schwersten verlässt. Wir müssen im Blute mit dissociabler und mit der an Alkalien gebundenen Kohlensäure rechnen. Bei dem Auspumpen des Blutes wird sämmtliche $\mathrm{CO}_{2}$ das Blut verlassen, wogegen bei meinem Verfahren nur diejenige Kohlensäure dem Blute entweichen wird, welche durch Herabsetzung des Partialdruckes auf Null herausgetrieben werden kann. Es wäre bei den künftigen Versuchen interessant, zu erforschen, wie sich die Menge der dissociablen Kohlensäure zur auspumpbaren Nenge verhält.

Wollen wir in unserem Apparat die Kohlınsäure mit schwacher Phosphorsäure aus dem Blute hinaustreiben, so können wir durch die Capillare $\mathrm{h}$ dieselbe langsam in kleiner Menge einsaugen lassen. Nur ist es dann nöthig, auch die Capillare $\mathrm{h}$ zu calibriren, da bei diesem Vorsuch das in der Capillare befindliche Blut ebenfalls in Betracht kommt.

Wollen wir das absorbirte Kohlenoxyd zur Probe der Genauigkeit des Apparates wieder heraustreiben, so sangen wir erst $1 \mathrm{ccm} 1 / 4$ proc. Ammoniaklösung ein und vermengen sie mit dem Blute, bis es lackfarben wird. Danach lassen wir Ferricyankalium hinzutreten, wodurch, wie es seit Hüfner-Haldane bekannt ist, das absorbirte $\mathrm{CO}$ frei wird, und wir erhalten wieder das originale Volumen des Kohlenoxyds. Bei diesem Experiment ist es nicht nöthig den Caliberwerth der Ansatzcapillare, durch welche die Reagentien eingesaugt werden, zu kennen, da doch das in der Capillare befindliche Blut kohlenoxydfrei ist und so das Resultat nicht beninträchtigen kann. Ich muss aber \%u diesem Experiment bemerken, dass die Ferricyanidprobe in dem Apparat nur mit der grössten Vorsicht ausgeführt werden kann, und es darf nur mit sehr schwachem negativen Druck angesaugt werden, da sich sonst leicht Schaum bildet, der sehr schwer wegzubringen ist. Die Ammoniakdämpfe stören das Resultat nicht, da, wie angegeben wurde, im Eudiometer sich ein Tropfen schwefelsaures Wasser befindet, welches die Ammoniakdämpfe absorbirt.

Die Möglichkeit der Fortsetzung des Versuches bis zu der Volumconstanz des Gases bietet eine Sicherheit im Arbeiten, welche bei keiner

1) Vergl. Loewy und Zuntz in Michaelis, Sauerstofftherapie. S. 52. Berlin, Hirschwald. 1906. 
anderen Methode möglich ist. Wir haben sozusagen den Versuch in der Hand und arbeiten so lange, bis wir uns überzeugt haben, dass wir nichts mehr zu erwarten haben. Es kann damit bei unserem Versuch die Möglichkeit ausgeschlossen werden, die Sättigung unvollkommen ausgeführt zu haben. Die Sauerstoffzährungsgefahr ist auch nicht grösser als hei dem Pumpenarbeiten, da der grösste Theil des Hämoglobins binnen sehr kurzer Zeit vom Sanerstoff befreit wird. Die Nenge des Blutes, mit der wir arbeiten, kann absolut genau festgestellt werden. Ausserdem kommt noch in Betracht, dass wir mil dem Apparat gut stimmende Resultate erzielt haben.

Das Pyrogallat geniesst nicht dasselbe Vortranen. Wichtjg ist für das Pyrogallat, sich an die Haldane'sche Vorschrift zu halten. Haldane nimmit zu Absorptionszwecken auf $100 \mathrm{~g}$ reinem KOH $50 \mathrm{~g}$ Wasser. Das entspricht einer 75 proc. KOH-Lösung und muss 1,55 spec. Gewicht haben. Zu $100 \mathrm{~g}$ dieser Jü̈sung fügt er $10 \mathrm{~g}$ Pyrogallussäure hinzu. Das so hergestellte Pyrogallat absorbirt nach meinen diesbrzüglichen Untersuchungen, die noch durch zahlreiche Luftanalysen unterstuitzt wurden, quantitativ den Sauterstoff und lässt keinen auf andere Weise nachweisbaren Rest zurück.

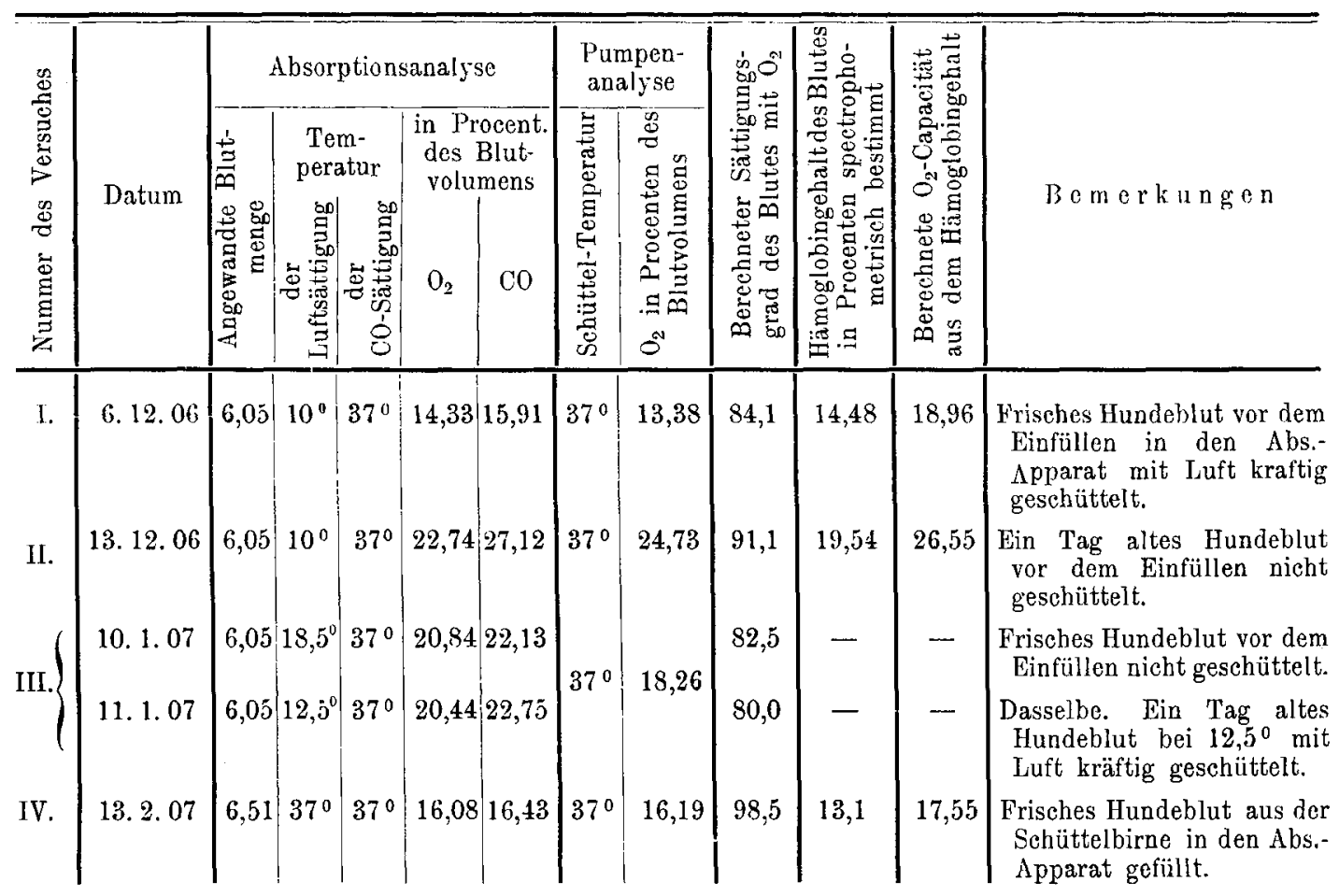

Bei den in der Tabelle befindlichen Versuchen legte ich vorerst den Hauptwerth auf die CO-Capacität. Vergleichen wir dic Zahlen mit den nach der spectropbotometrischen Bestimmung berechneten Saucrstoffcapacitätszahlen, so finden wir bei Versuch I und $V$, dass die berechnete Zahl, wenn wir bei der Berechnung die Hüfner'sche Mittelæahl von 
$1,34 \mathrm{ccm}$ für $1 \mathrm{~g}$ Hämoglobin einsetzen, um 2,95 pCt. resp. 1,12 pCt. grösser und bei Vers. II um 0,57 pCt. kleiner ist. Wir wissen aber, dass diese Hüfner'sche Mittelzahl ziemlich grosst Sehwankungen zeigt. Immerhin können sic zu einem informativen Vergleich herangezogen werden.

Vergleichen wir die durch Absorption gewonnenen Zahlen mit den durch Pumpe gewonnenen $\mathrm{O}_{2}$-Werthen, so sehen wir zunächst, dass diese stets grösser sind als die letzteren. lis ist dies ja auch nicht anders zu erwarten, indem wir doch wissen, dass die Sätigung mit Saverstoff bei $150 \mathrm{~mm}$ Partialdruck und $37^{\circ} \mathrm{C}$. nur etwa $88 \mathrm{pCl}$. beträgt, im Gegensatz zu dem Kohlenoxyd, wo wir 99-100 pCt. Sättigung zu erwarten haben. Bererhnen wir unter der Annahme, dass die CO-Zahlen voller Sättigung intsprechen, aus den durch Pumpenanalyse gefundenen $\mathrm{O}_{2}$-Werthen dic procentige Sauerstoffsättigung des Blutes bei atmosphärischer Luft und bei $37^{\circ}$, so finden wir, dass im Vers. 184,1 , II 91,1 , III 82,5 und 80,0 , IV 98,5 pCt. $0_{2}$ der absoluten Anfnahmefähigkeit enthalten war.

Die dureh Pumpe und durch Austreibung gewonnenen Sauerstoffzahlen sind bei meinen Versuchen, ausser Versuch IV, nicht mit einander zu vergleichen, indem kein Gewicht auf die $\mathrm{O}_{2}$-Sättigung vor der Einfüllung im Absorptionsapparat gelegt wurde. Nur bei Vers. IV, wo direct aus der Schüttelbirne das Blut theils in die Pumpe, theils in den Apparat gebracht wurde, ist auf dieses Moment geachtet worden und hier beträgt die Differenz zwischen den beiden, auf verschicdenen Wegen gefundenen Werthen nicht mehr als $0,11 \mathrm{Vol}$-pCt.

Die Fehlergrenze der Methode zeigt der Doppelversuch III. Die Differenz ist bei den zwei CO-Zahlen 0,52 , bei den $\mathrm{O}_{2}$-Zahlen 0,4 pCt.

Dass bei diesem Versuch die durch Austreiben gefundenen Sauerstoffzahlen grösser sind als die ausgepumpte Menge, finden ihre Erklärung in den verschiedenen Temperaturen, bei welchen das Blut mit Luft geschüttelt wurde. Wir finden im selben Sinne Differenzen auch bei Vers. I, wogegen aus Versuehsblut No. II, bei welchem das einen Tag alte Blut absichtlich nicht vor der Einfüllung geschüttelt wurde, mehr $\mathrm{O}_{2}$ nach der Sättigung bei $37^{\circ} \mathrm{C}$. ausgepumpt als ausgetrieben wurde.

Bezüglich der Kohlensäure verweise ich auf das angeführte Borechnungsbeispiel im Anhang, dem der Vers. III zu Grunde gelegt ist. Wir sehen, dass dic ausgetriebene Menge bei jeder Etappe des Versuches abnimmt, und dass wir bei weiterem Fortsetzen des Versuches wahrscheinlich dazu gekommen wären, sämmtliche $\mathrm{CO}_{2}$ aus dem Blute zu treiben.

Ich bin weit davon entfernt diese Versuche und die Resultate für erschöpfend zu betrachten und damit die weitere Controle der Methode und des Apparates für überflüssig zu halten. Ich bin mir dessen sehr bewusst, dass noch Versuche fehlen, wo die CO-Capacität durch Pumpe und Absorption zu bestimmen gewesen wäre, dass die Kohlensäure bis zum letəten dissociablen Rest hätte herausgetrieben werden müssen, und dass die Zahlen der Kinzel- und Doppelbestimmangen noch viel zu gering 
sind, um aus ihnen ein endgültiges Urtheil zu bilden. Da ich aber mein gestecktes Ziel, das ich mit denı Apjarat zu erreichen glaubte, auf andere Weise bequemer und leichter erreicht habe, und in absehbarer Zeit nicht dazu kommen werde, mit dem Apparat weiter arbeiten zu können, habe ich mich entschlossen, dieses analytische Verfahren, soweit es bis jetzt ausgebildet ist, zu veröffentlichen.

Ich thue dies in der festen Ueberzeugung, dass es bei nöthiger Fertigkeit gelingen wird, mit dem Apparat einige wichtige Capitel aus der Blutphysiologie der Lösung näher zu bringen, und um derartige Arbeiten zu erleichtern, hielt ich es für richtig, sämmtliche methodischen Einzelheiten in der Weise, wie es geschehen ist, anzugeben.

Die nächstliegenden Fragen, die mit dem Apjarat zu lösen sind, kann ich in Folgendem zusammenfassen:

1. Den Sauerstoffgehalt des Blutes im Verhältniss zur Kohlenoxydcapacität und Hämoglobingehalt in normalen und krankhaften Fällen festzustellen.

2. Die Kohlenoxydcapacitätscurve bei verschiedenem Druck zu construiren.

3. Die Kohlenoxydcapacitätscurve bei versehiedener Temperatur zu untersuchen.

4. Die quantitative Bestimmung der Kohlenoxydmenge in der Luft.

Zum Schluss sage ich dem Herrn Geheimrath Zuntz meinen innigsten Dank für die vielfache Anregung und Hülfe, mit welcher er meine $\Lambda$ rbeil gefördert hat.

\section{Anhang.}

Berechnungsbeispiel.

Datum des Versuches 10. 1. 1907. Hundeblut.

Pumpenanalyse ergiebt nach Schütteln im Scnüttelapparat bis $37^{\circ} \mathrm{C}$. für $\mathrm{O}_{2}=$ 18,26 Volumenprocente.

Bestimmung mit dem Absorptionsapparat.

Blut ein Tag alt auf Eis aufbewahrt. Angewandte Blutmenge 6,05 ccm. Einfüllungstemperatur $18,5^{\circ} \mathrm{C}$.

$$
\begin{aligned}
& \text { Gas }\left\{\begin{array}{l}
\text { Volumen }=31,82 \\
\text { Temp. }=19,9^{\circ} \mathrm{C} .
\end{array}\right. \\
& \text { Barometer }\left\{\begin{array}{l}
770,06 \mathrm{~mm} \\
19,8^{\circ} \mathrm{C} .
\end{array}\right.
\end{aligned}
$$

Temperatur im Blutrecipienten $37^{\circ} \mathrm{C}$.

Mischungsetappen $8 \mathrm{mal}$ wiederholt.

Ablesung nach Vollendung der Absorption $30,30 \mathrm{ccm}$.

Caliber-Correctur $=0,0211$.

$31,82 \mathrm{ccm}$ bei obenstehenden Verhältnissen reducirt $=29,31 \mathrm{ccm}$.

Temperaturin den Blutrecipienten.

Nach 10 Minuten Mischung.

Gasvolum 32,645

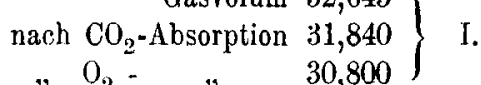

Nach weiteren 15 Minuten.

Gasvolum 31,200

nach $\mathrm{CO}_{2}$-Absorption 30,760$\}$ II. 
Ein neuer Ipparat zur Bostimmung des Sauerstolfgchaltes etc.

Nach 12 Minuten.

Gasvolum 30,910

nach $\mathrm{CO}_{2}$-Absorption 30,530

, $\mathrm{O}_{2}-\quad, \quad 30,440$

Nach 10 Minuten.

Gasvolum 30,570

nach $\mathrm{CO}_{2}$-Absorption 30,370

" $\mathrm{O}_{2}-\quad 30,350$

Nach 10 Minuten.

Gasvolum 30,420

nach $\mathrm{CO}_{2}$-Absorption 30,310$\}$ VIl.
Nach 10 Minuten.

Gasvolum 30,685

IlI. nach $\mathrm{CO}_{2}$-Absorption 30,430$\} \mathrm{IV}$.

$" \mathrm{O}_{2}-n \quad 30,395$

Nach 10 Minuten.

Gasvolum 30,485

nach $\mathrm{CO}_{2}$-Absorption 30,340$\} \mathrm{V}$.

$n \mathrm{O}_{2}{ }^{-} \quad n \quad 30,320$

Nach 15 Minuten.

Gasvolum 30,360

IIach $\mathrm{CO}_{2}$-Absorption 30,300$\}$ Vlil.

$n \mathrm{O}_{2}=n, 30,300$

Nach diesen analytischen Daten berechnen sich folgende Zahlen für die 0 - und $\mathrm{CO}_{2}$ - - bgabe des Blutes und das von ihm aufgenommenen $\mathrm{CO}$ für die cinzelnen Etappen des Versuchs.

\begin{tabular}{r|l|l|l}
\hline \hline Etappe & $0_{2}$ & $\mathrm{CO}_{2}$ & $\mathrm{CO}$ \\
\hline I. & 1,04 & 0,805 & 1,02 \\
II & 0,21 & 0,44 & 0,25 \\
III. & 0,09 & 0,38 & 0,11 \\
IV & 0,035 & 0,255 & 0,055 \\
V & 0,02 & 0,20 & 0,045 \\
VI & 0,02 & 0,145 & 0,03 \\
VII & 0,01 & 0,11 & 0,01 \\
VIII & 0,00 & 0,06 & 0,00 \\
\hline Summa: & 1,425 & 2,395 & 1,520
\end{tabular}

Berechnugg des Sauerstoffgehaltes des Blutes.

$$
\begin{aligned}
& \mathrm{O}_{2} \text { freigeworden } 1,425 \mathrm{ccm} \\
& \text { Calibercorrectur } 0,021 " \\
& \frac{1,404}{2}
\end{aligned}
$$

1,404 reducirt $=1,293 \mathrm{ccm}=21,37$ Volumprocente des Blutes.

$21,37-0,53$ (phys. absorbirt) $=20,84$ Volumprocente $0_{2}$ im Blute.

Berechnung der Kohlenoxydcapacität.

Die Abnahme des CO betrug 1,520, d. h. nach Abzug der Calibercorrectur $1,499 \mathrm{ccm} .1,499 \mathrm{ccm}$ reducirt $=1,381 \mathrm{ccm} .1,381 \mathrm{ccm}=22,82$ Volumprocente.

$22,82+1,31$ pCt. phys. absorb. $\mathrm{N}$ bei $18,5^{\circ} \mathrm{C}$. $-2,00 \mathrm{pCt}$. phys. absorb. CO bei $37^{\circ} \mathrm{C}$. $=22,13$ Volumprocente C0-Capacitä. 